\title{
Providing End-of-Life Care to Patients: Critical Care Nurses' Perceived Obstacles and Supportive Behaviors
}

\author{
Renea L. Beckstrand \\ Brigham Young University - Provo, renea@byu.edu \\ Karin T. Kirchhoff \\ University of Wisconsin-Madison
}

Follow this and additional works at: https://scholarsarchive.byu.edu/facpub

Part of the Critical Care Nursing Commons, Other Nursing Commons, and the Palliative Nursing Commons

\section{Original Publication Citation}

Beckstrand, R. L., \& Kirchhoff, K. T. (2005). Providing end-of-life care to dying patients: critical care nurses' perceived obstacles and supportive behaviors. American Journal of Critical Care, 14(5), 395-403.

\section{BYU ScholarsArchive Citation}

Beckstrand, Renea L. and Kirchhoff, Karin T., "Providing End-of-Life Care to Patients: Critical Care Nurses' Perceived Obstacles and Supportive Behaviors" (2005). Faculty Publications. 5300.

https://scholarsarchive.byu.edu/facpub/5300

This Peer-Reviewed Article is brought to you for free and open access by BYU ScholarsArchive. It has been accepted for inclusion in Faculty Publications by an authorized administrator of BYU ScholarsArchive. For more information, please contact ellen_amatangelo@byu.edu. 


\section{Providing End-of-Life Care to Patients: Critical Care Nurses' Perceived Obstacles ANd SupPortive BehaViors}

By Renea L. Beckstrand, RN, PhD, CCRN, and Karin T. Kirchhoff, RN, PhD. From Brigham Young University, Provo, Utah (RLB), and University of Wisconsin, Madison, Wis (KTK).

- BACKGROUND Critical care nurses care for dying patients daily. The process of dying in an intensive care unit is complicated, and research on specific obstacles that impede delivery of end-of-life care and/or supportive behaviors that help in delivery of end-of-life care is limited.

- OBJECTIVE To measure critical care nurses' perceptions of the intensity and frequency of occurrence of (1) obstacles to providing end-of-life care and (2) supportive behaviors that help in providing end-oflife care in the intensive care unit.

- Methods An experimental, posttest-only, control-group design was used. A national, geographically dispersed, random sample of members of the American Association of Critical-Care Nurses was surveyed.

- RESULTS The response rate was 61.3\%, 864 usable responses from 1409 eligible respondents. The highest scoring obstacles were frequent telephone calls from patients' family members for information, patients' families who did not understand the term lifesaving measures, and physicians disagreeing about the direction of a dying patient's care. The highest scoring supportive behaviors were allowing patients' family members adequate time alone with patients after death, providing peaceful and dignified bedside scenes after death, and teaching patients' families how to act around a dying patient.

- CONCLUSIONS The biggest obstacles to appropriate end-of-life care in the intensive care unit are behaviors of patients' families that remove nurses from caring for patients, behaviors that prolong patients' suffering or cause patients pain, and physicians' disagreement about the plan of care. (American Journal of Critical Care. 2005;14:395-403)

\section{CE Online}

To receive CE credit for this article, visit the American Association of Critical-Care Nurses' (AACN) Web site at http://www.aacn.org, click on "Education" and select "Continuing Education," or call AACN's Fax on Demand at (800) 222-6329 and request item No. 001116.

To purchase reprints, contact The InnoVision Group, 101 Columbia, Aliso Viejo, CA 92656. Phone, (800) 809-2273 or (949) 362-2050 (ext 532); fax, (949) 362-2049; e-mail, reprints@aacn.org.
$\mathrm{D}$ eath is a fact of life. Providing appropriate care for patients who are dying is a chief concern in the United States today. With more than 2.4 million deaths annually, ${ }^{1}$ most deaths $(80 \%)$ in the United States occur in hospitals and involve patients who are 65 years or older. ${ }^{2,3}$ On average, within 6 months before death, about $11 \%$ of Medicare recipients spend more than 7 days in an intensive care unit (ICU). ${ }^{4}$ Often, critical care nurses are responsible for caring for these dying patients because about one fifth of ICU patients die while hospitalized. ${ }^{5}$

Death as it occurs in the ICU is neither simple nor natural. ${ }^{6}$ Caring for dying patients and their families is thought to be most stressful and painful to the nurses 
who must constantly attend the patients ${ }^{7-9}$; other healthcare providers can visit and then walk away. ${ }^{6,10}$ Despite adequate documentation of the difficulties and inadequacies of providing end-of-life care to patients, ${ }^{9,11-18}$ research from the perspective of critical care nurses on obstacles and/or supportive behaviors that either restrict or promote good care of dying patients is limited. ${ }^{16,19-21}$ Although some studies ${ }^{19,22}$ provide information on obstacles, no reports provide data on both the frequency and intensity of specific obstacles or supportive behaviors.

\section{Caring for dying patients is most stressful to nurses who must constantly attend patients, whereas other providers can visit and then walk away.}

The study reported here was designed to measure critical care nurses' perceptions of both the intensity and frequency of obstacles and supportive behaviors in providing end-of-life care to patients and their families. The research questions included the following:

- Which obstacles to providing end-of-life care do critical care nurses perceive as both the most intense and the most frequently occurring?

- Which supportive behaviors in providing end-oflife care do critical care nurses perceive as both the most intense and the most frequently occurring?

\section{Methods Sample}

A geographically dispersed, random sample of 1500 members of the American Association of Critical-Care Nurses (AACN) was surveyed. Potential respondents were randomly selected from a membership of 68000 . The subjects were currently employed staff nurses who had worked at least part-time in a critical care setting, were living in the United States, were able to read English, and had cared for at least 1 patient who was at the end of life.

\section{Instrument}

A questionnaire, ${ }^{20}$ National Survey of Critical-Care Nurses Regarding End-of-Life Care, was developed, pretested, and administered in 1998. The original questionnaire was mailed to 300 randomly selected members of AACN. The highest rated obstacle in the first study was patients' families continually calling nurses for information on the patients. For this study, the questionnaire was adapted by adding the component of frequency of occurrence, for both obstacles and supportive behaviors, to determine if the most frequently listed items reported in the original study were still the most frequently listed when nurses were also asked to report how often each item occurred $(0=$ never occurs, $5=$ always occurs).

Other changes from the first questionnaire included adding 5 new obstacles and a single support item as suggested by the nurses in the original study. The added obstacle items were as follows:

1. physicians who do not let patients die from the disease process,

2. physicians who are evasive and avoid having conversations with family members,

3. multiple physicians involved with a patient who differ in opinion about the direction care should go,

4. continuing to provide treatments to dying patients because of financial benefits to the hospital, and

5. when nurses' opinions about the direction a patient's care should go are not requested, not valued, or not considered.

One additional supportive behavior item was added about the use of unlicensed personnel available to help care for dying patients. The final questionnaire contained 72 items: 29 obstacle items, 24 supportive behavior items, 4 open-ended items for nurses to add any items that the survey did not cover, and 15 demographic questions. Approval for the study was obtained from the appropriate institutional review board.

The first mailing was sent to the entire sample of 1500 nurses. A second mailing was sent approximately 5 weeks later to all nonresponders $(n=936)$. A third mailing of the entire survey was sent to the remaining nonresponders approximately 8 weeks after the second mailing $(n=686)$. The questionnaires were returned in pre-addressed postage-paid envelopes that were provided to the nurses for their convenience.

The Cronbach $\alpha$ was .89 for the 29 obstacle size items, suggesting that scale scores were internally consistent. This $\alpha$ was slightly higher than the $\alpha(.86)$ in the first study because of the addition of 5 pertinent obstacle items suggested by the nurses in the original study. Internal consistency estimates of reliability were also computed for the 29 obstacle frequency items (.89), the 24 supportive behavior items (.86), and the 24 supportive behavior frequency items (.81). The $\alpha$ for the supportive behavior data was slightly higher than the $\alpha$ (.82) in the original study because of the addition of an item recommended by the nurses in the original study.

\section{Data Analysis}

Responses were analyzed by using SPSS software (SPSS, Inc, Chicago, Ill). Two researchers checked the accuracy of the entered data for all returned questionnaires. Frequencies, measures of central tendency and 
dispersion, and reliability statistics were calculated for all obstacle and supportive behavior items. Items were then ranked on the basis of their mean scores to determine which ones were perceived to be the most intense obstacles or supportive behaviors and which items were perceived to occur most often. Each item's intensity mean was multiplied by the item's frequency mean to obtain a perceived intensity score for the obstacles ${ }^{23}$ or a perceived supportive behavior score for the supportive behavior items. Intensity scores for both obstacles and supportive behaviors were then ranked from highest score to lowest score.

\section{Results}

\section{Demographic Data}

Of the 1500 potential respondents, 955 returned the questionnaire. Of these, 91 were eliminated from the study sample either because the questionnaire could not be delivered $(n=1)$ or because the recipients reported that they were ineligible $(n=90)$ because of retirement, health issues, or a change in position. Usable responses were received from 864 nurses, or about $1.3 \%$ of the total AACN membership (as reported in 2002). The complete demographic information is reported in Table 1.

As determined by the mailing addresses of all 955 surveys returned, respondents (both usable and ineligible) lived in the following time zones: Eastern $(n=512)$, Central $(n=230)$, Mountain $(n=48)$, Pacific $(n=155)$, or other (Alaska, Hawaii/Aleutians, or Army Post Office/ military address; $n=10$ ). More returns were received from the Eastern and Central time zones because of the higher percentage of AACN members who lived in these areas.

\section{Obstacles}

Highest Scoring Items. On a scale of 0 (not an obstacle) to 5 (extremely large obstacle), mean intensity scores for items in the obstacle section of the questionnaire ranged from 1.62 to 4.03 (Table 2). The 3 items perceived as the most intense obstacles to providing end-of-life care were having multiple physicians who differed in opinion about the direction of a patient's care (mean $=4.03)$, patients' family members and friends who continually called a nurse for an update on the patients' condition rather than calling the designated contact person (mean $=4.02)$, and physicians who were evasive and avoided conversations with patients' family members $($ mean $=4.00)$.

The largest obstacle to providing end-of-life care was multiple physicians who differed in opinion about the direction of a patient's care.

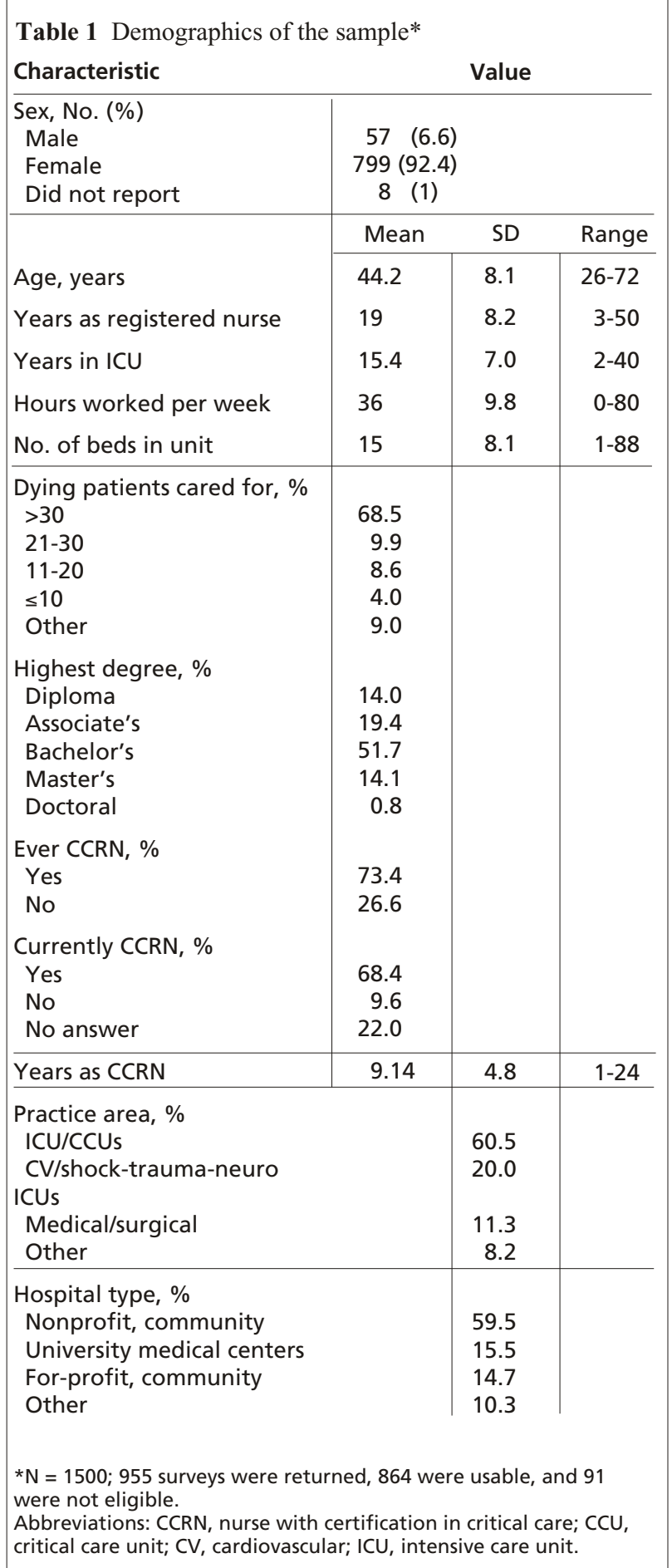

Of the other top 10 obstacle items, 4 involved issues with patients' families: families not understanding what the term lifesaving measures really meant $($ mean $=3.91)$, angry family members $($ mean $=3.85)$, families not accepting a patient's poor prognosis $($ mean $=3.64)$, and families wanting life-sustaining 


\begin{tabular}{|c|c|c|c|c|c|c|c|}
\hline \multirow[b]{2}{*}{ Obstacles } & \multicolumn{3}{|c|}{ Intensity* } & \multicolumn{3}{|c|}{ Frequency $^{\dagger}$} & \multirow[b]{2}{*}{ PIS $^{\ddagger}$} \\
\hline & Mean & SD & Rank & Mean & SD & Rank & \\
\hline $\begin{array}{l}\text { 1. Family continually calls nurse for update } \\
\text { rather than the designated contact person }\end{array}$ & 4.02 & 0.98 & 2 & 3.69 & 0.95 & 1 & 14.83 \\
\hline $\begin{array}{l}\text { 2. Family not understanding the term } \\
\text { "life-saving measures" and its implications }\end{array}$ & 3.91 & 1.00 & 4 & 3.31 & 1.01 & 3 & 12.94 \\
\hline 3. Physicians differing in opinion about care of a patient & 4.03 & 1.10 & 1 & 2.92 & 1.11 & 7 & 11.77 \\
\hline 4. Physicians evasive and avoid family & 4.00 & 1.09 & 3 & 2.90 & 1.10 & 8 & 11.60 \\
\hline $\begin{array}{l}\text { 5. Nurse too busy offering life-saving } \\
\text { measures to provide quality end-of-life care }\end{array}$ & 3.58 & 1.10 & 11 & 3.07 & 1.04 & 5 & 10.99 \\
\hline 6. Families not accepting poor patient prognosis & 3.64 & 1.01 & 8 & 2.94 & 0.87 & 6 & 10.70 \\
\hline 7. Nurse having to deal with angry family members & 3.85 & 1.03 & 5 & 2.71 & 0.97 & 13 & 10.43 \\
\hline $\begin{array}{l}\text { 8. Nurse having to deal with distraught } \\
\text { family while still caring for patient }\end{array}$ & 3.24 & 1.13 & 17 & 3.21 & 1.04 & 4 & 10.40 \\
\hline $\begin{array}{l}\text { 9. Nurse not being able to communicate with patient } \\
\text { to learn of his/her wishes regarding treatment due } \\
\text { to sedation or depressed neurological status }\end{array}$ & 3.63 & 1.06 & 9 & 2.84 & 1.03 & 9 & 10.31 \\
\hline $\begin{array}{l}\text { 10. Physicians won't allow patient } \\
\text { to die from the disease process }\end{array}$ & 3.72 & 1.18 & 7 & 2.74 & 1.08 & 12 & 10.19 \\
\hline $\begin{array}{l}\text { 11. Family requesting life-saving measures } \\
\text { contrary to patient's wishes }\end{array}$ & 3.81 & 1.18 & 6 & 2.62 & 1.06 & 14 & 9.98 \\
\hline $\begin{array}{l}\text { 12. Physicians overly optimistic to } \\
\text { family about the patient surviving }\end{array}$ & 3.50 & 1.09 & 13 & 2.81 & 0.92 & 10 & 9.84 \\
\hline $\begin{array}{l}\text { 13. Nurse called away from patient } \\
\text { and family to perform other duties }\end{array}$ & 3.27 & 1.15 & 15 & 2.81 & 1.16 & 11 & 9.19 \\
\hline $\begin{array}{l}\text { 14. Patient's treatments continue, } \\
\text { although painful or uncomfortable }\end{array}$ & 3.58 & 1.23 & 10 & 2.53 & 1.10 & 16 & 9.06 \\
\hline 15. Family fighting about life support & 3.57 & 1.10 & 12 & 2.47 & 0.89 & 17 & 8.82 \\
\hline 16. Nurse's opinion about patient's care not valued & 3.45 & 1.30 & 14 & 2.43 & 1.18 & 18 & 8.38 \\
\hline 17. Nurse knowing poor prognosis before family & 2.29 & 1.56 & 24 & 3.39 & 1.11 & 2 & 7.76 \\
\hline $\begin{array}{l}\text { 18. Family members not having private } \\
\text { place to grieve at patient's bedside }\end{array}$ & 2.85 & 1.57 & 19 & 2.61 & 1.49 & 15 & 7.44 \\
\hline $\begin{array}{l}\text { 19. Family legal action is a threat, thus patient } \\
\text { intensive care continues despite poor prognosis }\end{array}$ & 3.24 & 1.33 & 16 & 2.21 & 1.17 & 19 & 7.16 \\
\hline 20. Patient having pain that is difficult to control or alleviate & 2.97 & 1.34 & 18 & 2.00 & 0.93 & 23 & 5.94 \\
\hline 21. Family not with the patient when he/she is dying & 2.71 & 1.18 & 20 & 2.13 & 0.81 & 20 & 5.77 \\
\hline $\begin{array}{l}\text { 22. Nurse not trained regarding family } \\
\text { grieving and quality end-of-life care }\end{array}$ & 2.64 & 1.36 & 21 & 2.11 & 1.20 & 21 & 5.57 \\
\hline 23. Families grieving in culturally diverse ways & 2.47 & 1.19 & 22 & 2.04 & 0.93 & 22 & 5.04 \\
\hline 24. Family visiting hours too liberal & 2.06 & 1.72 & 28 & 1.96 & 0.56 & 24 & 4.04 \\
\hline $\begin{array}{l}\text { 25. Family grieving time limited to } \\
\text { accommodate new admissions }\end{array}$ & 2.47 & 1.59 & 23 & 1.49 & 1.10 & 27 & 3.68 \\
\hline $\begin{array}{l}\text { 26. Unavailability of ethics board or committee } \\
\text { to review difficult patient cases }\end{array}$ & 2.28 & 1.69 & 24 & 1.60 & 1.41 & 26 & 3.65 \\
\hline $\begin{array}{l}\text { 27. Family not having a support person } \\
\text { eg, social worker or religious leader }\end{array}$ & 2.18 & 1.47 & 26 & 1.63 & 1.13 & 25 & 3.55 \\
\hline 28. Family visiting hours too restrictive & 1.62 & 1.69 & 29 & 1.48 & 1.40 & 28 & 2.40 \\
\hline $\begin{array}{l}\text { 29. Continuing to provide advanced treatments to dying } \\
\text { patients because of financial benefits to hospital }\end{array}$ & 2.10 & 1.86 & 27 & 0.98 & 1.13 & 29 & 2.06 \\
\hline $\begin{array}{l}\text { *Choices were } 0 \text {, not an obstacle, to } 5 \text {, extremely large obstacle. } \\
{ }^{\dagger} \text { Choices were } 0 \text {, never occurs, to } 5 \text {, always occurs. } \\
{ }^{\ddagger} \text { PIS = mean for intensity multiplied by mean for frequency. }\end{array}$ & & & & & & & \\
\hline
\end{tabular}


measures to be continued even though a patient's advance directive requested no such treatment (mean $=3.81$ ).

The lowest scoring obstacle items were related to visiting hours. Visiting hours being too restrictive (mean $=1.62$ ) was the lowest rated item; visiting hours being too liberal was the second lowest (mean $=2.06)$.

Frequently Occurring Items. On a scale of 0 (never occurs) to 5 (always occurs), mean frequency scores for the items in the obstacle section of the questionnaire ranged from 0.98 to 3.69 (Table 2). The 3 items with the highest means were having patients' friends and family continually call a nurse rather than the designated contact person for an update of a patient's condition (mean $=3.69$ ), nurses knowing a patient's poor prognosis before the patient's family knew the prognosis (mean $=3.39$ ), and patients' family members not understanding what the term lifesaving measures really meant (mean $=3.31)$.

Perceived Intensity Scores. To determine which obstacle items were perceived as both the most intense and the most frequently occurring, a perceived intensity score was calculated (mean obstacle intensity multiplied by mean obstacle frequency). Scores ranged from 2.06 to 14.83 (Table 2). The item receiving the highest score was having patients' families and friends continually call a nurse rather than calling the designated family member for updates on a patient's condition (mean=14.83). This item not only had the highest score but also was 1.89 points higher than the next closest item. None of the other 28 items had as large a difference between perceived intensity scores.

\section{The most frequently occurring obstacle to providing end-of-life care was patients' friends and family continually calling a nurse for an update on the patient's condition rather than the designated contact person.}

Of the remaining top 10 obstacles with the highest perceived intensity, 4 involved family issues: families not understanding what lifesaving measures really meant (12.94), family members who did not accept that a patient was dying (10.70), nurses having to deal with angry members of a patient's family (10.43), and nurses having to deal with a patient's distraught family members while still caring for the patient (10.40).

Items with the lowest perceived intensity scores included the concepts that advanced treatments were being provided to dying patients so that the hospital would benefit financially (2.06), that visiting hours were too restrictive (2.40), and that no support persons, such as social workers or religious leaders, were available to a patient's family (3.55).

\section{Supportive Behaviors}

Highest Scoring Items. On a scale of 0 (not a support) to 5 (extremely intense support), mean intensity scores for the items in the supportive behaviors section of the questionnaire ranged from 2.61 to 4.59 (Table 3). The items with the highest mean scores were agreement among physicians about the direction a patient's care should go (mean $=4.59)$, family members' acceptance that a patient was dying $($ mean $=4.57)$, and designation of a single family member as the contact person for all the other family members about information on the patient (mean=4.49). Of the remaining top 11 items, 4 dealt with supportive behaviors that occurred after a patient's death and were in some way helpful to the patient's family. Behaviors perceived as the least supportive included the availability of unlicensed personnel to help provide care $($ mean $=2.61)$ and having patients' family members physically help care for a dying patient (mean $=3.20$ ).

Frequently Occurring Items. On a scale of 0 (never occurs) to 5 (always occurs), mean scores for frequency of items in the supportive behaviors section of the questionnaire ranged from 0.77 to 3.96 (Table 3). Providing a patient's family members with unlimited time alone with the patient after death $($ mean $=3.96$ ) and creating a peaceful, dignified bedside scene after a patient's death (mean $=3.90)$ were the 2 most frequently occurring supportive behaviors. Other frequently occurring behaviors were teaching patients' families how to act around a dying patient $($ mean $=3.66)$ and nurses allowing a patient's family unlimited access to the patient (mean=3.28).

Supportive behaviors that occurred least frequently were having members of the ethics committee routinely attend unit rounds $($ mean $=0.77$ ) and having unlicensed personnel available to help care for dying patients $($ mean $=1.34)$.

Perceived Supportive Behaviors Scores. To determine which items were perceived as both the most supportive and the most frequently occurring, perceived supportive behaviors scores were calculated (mean intensity score multiplied by mean frequency score). The range for all items was 2.63 to 17.58 (Table 3). The 2 items perceived as most supportive and most frequently occurring were allowing a patient's family members adequate time alone with the patient after death (17.58) and providing a peaceful, dignified bedside scene (17.36). 


\begin{tabular}{|c|c|c|c|c|c|c|c|}
\hline \multirow[b]{2}{*}{ Supportive behavior } & \multicolumn{3}{|c|}{ Intensity* } & \multicolumn{3}{|c|}{ Frequency $^{\dagger}$} & \multirow[b]{2}{*}{ PSBS } \\
\hline & Mean & SD & Rank & Mean & SD & Rank & \\
\hline $\begin{array}{l}\text { 1. Family members having adequate time to be } \\
\text { alone with the patient after his/her death }\end{array}$ & 4.44 & 0.70 & 5 & 3.96 & 0.96 & 1 & 17.58 \\
\hline $\begin{array}{l}\text { 2. Family members having a peaceful and } \\
\text { dignified bedside scene }\end{array}$ & 4.45 & 0.69 & 4 & 3.90 & 0.96 & 2 & 17.36 \\
\hline 3. Families being taught how to act around dying patient & 4.19 & 0.75 & 9 & 3.66 & 0.89 & 3 & 15.33 \\
\hline $\begin{array}{l}\text { 4. Family members show gratitude to nurse } \\
\text { for care provided to patient who has died }\end{array}$ & 4.28 & 0.83 & 7 & 3.05 & 0.99 & 5 & 13.05 \\
\hline 5. Physicians agreeing about direction of patient care & 4.59 & 0.64 & 1 & 2.73 & 0.95 & 8 & 12.53 \\
\hline 6. Family members accept that patient is dying & 4.57 & 0.61 & 2 & 2.67 & 0.77 & 9 & 12.20 \\
\hline 7. Families having unlimited access to the dying patient & 3.71 & 1.24 & 17 & 3.28 & 1.10 & 4 & 12.17 \\
\hline $\begin{array}{l}\text { 8. Nurse drawing on previous experience with } \\
\text { the critical illness or death of a family member }\end{array}$ & 3.83 & 0.98 & 15 & 2.98 & 1.09 & 6 & 11.41 \\
\hline $\begin{array}{l}\text { 9. Family designating one family member as } \\
\text { contact person for the rest of the family }\end{array}$ & 4.49 & 0.72 & 3 & 2.53 & 1.02 & 11 & 11.36 \\
\hline 10. Nurses offer words of support to each other & 3.90 & 1.15 & 14 & 2.81 & 1.18 & 7 & 10.96 \\
\hline $\begin{array}{l}\text { 11. Nurse having enough time to prepare the } \\
\text { family for patient's death }\end{array}$ & 4.28 & 0.74 & 8 & 2.48 & 0.82 & 12 & $10.61^{\S}$ \\
\hline $\begin{array}{l}\text { 12. Nurses scheduled so that patient } \\
\text { receives continuity of care }\end{array}$ & 4.13 & 0.85 & 10 & 2.57 & 1.07 & 10 & $10.61^{\S}$ \\
\hline 13. Unit designed so family has a place to grieve in private & 4.31 & 0.85 & 6 & 2.46 & 1.46 & 13 & 10.60 \\
\hline $\begin{array}{l}\text { 14. Staff compiles all paper work to be signed } \\
\text { by the family before they leave the unit }\end{array}$ & 3.99 & 1.10 & 12 & 2.41 & 1.41 & 14 & 9.62 \\
\hline 15. Nurses offer supportive physical touch to each other & 3.64 & 1.25 & 19 & 2.33 & 1.29 & 15 & 8.48 \\
\hline $\begin{array}{l}\text { 16. Physicians meet in person with the } \\
\text { family after the patient's death }\end{array}$ & 4.14 & 0.91 & 11 & 1.90 & 1.21 & 21 & 7.87 \\
\hline $\begin{array}{l}\text { 17. Nurses having a supportive person outside of the } \\
\text { work setting to listen after the death of a patient }\end{array}$ & 3.57 & 1.36 & 21 & 2.16 & 1.60 & 16 & 7.71 \\
\hline 18. Physicians putting hope in tangible terms for family & 3.66 & 1.26 & 18 & 2.06 & 0.96 & 18 & 7.54 \\
\hline $\begin{array}{l}\text { 19. Letting the social worker or religious leader } \\
\text { take primary care of the grieving family }\end{array}$ & 3.59 & 1.09 & 20 & 2.08 & 1.18 & 17 & 7.47 \\
\hline $\begin{array}{l}\text { 20. Nurse talking with patient about his or her } \\
\text { feelings and thoughts about dying }\end{array}$ & 3.92 & 0.91 & 13 & 1.85 & 0.92 & 22 & 7.25 \\
\hline $\begin{array}{l}\text { 21. Nurses take care of patients while affected nurse } \\
\text { "gets away" for a moment after the death of a patient }\end{array}$ & 3.71 & 1.23 & 16 & 1.94 & 1.36 & 19 & 7.20 \\
\hline 22. Family physically helping to care for the dying patient & 3.20 & 1.15 & 23 & 1.92 & 0.94 & 20 & 6.14 \\
\hline $\begin{array}{l}\text { 23. Having unlicensed personnel available to } \\
\text { help care for dying patients }\end{array}$ & 2.61 & 1.51 & 24 & 1.34 & 1.21 & 23 & 3.50 \\
\hline $\begin{array}{l}\text { 24. Ethics committee constantly involved in the unit, } \\
\text { so they are involved from the beginning should } \\
\text { an ethical situation arise later }\end{array}$ & 3.42 & 1.38 & 22 & 0.77 & 1.15 & 24 & 2.63 \\
\hline $\begin{array}{l}\text { *Choices were } 0 \text {, not a support, to } 5 \text {, extremely intense support. } \\
\text { 'Choices were } 0, \text { never occurs, to } 5 \text {, always occurs. } \\
\text { "PSBS = mean for intensity multiplied by mean for frequency. } \\
\text { \$Tie is due to rounding of numbers. }\end{array}$ & & & & & & & \\
\hline
\end{tabular}

Three other highly scoring items were related to nurse-family interactions: teaching patients' families how to act around a dying patient (15.33), having members of a patient's family thank the patient's nurse, in 
some way, for caring for the patient (13.05), and nurses using their own experiences with a critical illness or death of a loved one to help a patient's family (11.41).

Acceptance by patients' families that the patients were dying (12.20), allowing patients' families unlimited access to the patients - even at the expense of the patients' care (12.17), and having patient's families designate a single contact person for all other family members for information about the patient (11.36) were also among the top 10 most intense and frequent supportive behaviors.

Items with the lowest perceived supportive behaviors scores included having members of the ethics committee routinely attend unit rounds (2.63), using unlicensed personnel to help care for dying patients (3.50), and having a patient's family members physically help care for the patient (6.14).

\section{Discussion}

Providing end-of-life care for patients and their families can be stressful for nurses because the nurses may be insufficiently trained to manage the process. ${ }^{6,724}$ Job stress associated with working in ICUs may lead to burnout or a state of emotional and physical exhaustion. ${ }^{23,25}$ As working conditions decline, job performance may deteriorate, the quality of care may diminish, and employee turnover may increase. ${ }^{23}$

The process of dying in an ICU can be messy, noisy, and complicated. ${ }^{6}$ Healthcare personnel who have chosen to work in an ICU environment can find the chaos associated with death unpleasant. ${ }^{6}$ A better understanding of the most intense and the most frequently occurring obstacles that restrict nurses from providing quality end-of-life care could lead to the development and testing of interventions to lower both the intensity and the frequency of these obstacles, thus lessening the burden of care. An understanding of the most intense and most frequent supportive behaviors could lead to the development of interventions to maintain the highly rated supportive behaviors and increase the lower rated supportive behaviors.

The response rate for our survey, after 3 mailings, was $61.3 \%$, slightly lower than the rate for the initial study (68.5\%). One possible reason for the difference is that the original survey was mailed during the early summer months, whereas the survey for this study was mailed in the fall. Most likely, fewer surveys were returned in this study because of the busy holidays that occur toward the end of the year.

Our results validate the information obtained in the original study and add to the literature in several ways. First, the top 2 obstacles in the original study were still perceived as the most intense in the survey for this study, despite the additional efforts at refinement of measuring. Second, the 3 additional obstacle items added to the survey as suggested by the nurses in the original study were rated as the $3 \mathrm{rd}$, 4th, and 10th most intense obstacles in this study. Third, obstacle items with low intensity scores in the original study also had the lowest intensity scores in this study.

Information on frequency of occurrence helped clarify the perceived intensity of obstacles; 6 of the obstacle items included in the original study continued to be among the top 10 most intense obstacles, thus validating their importance. Four items dropped below 10th position and were obstacles of less intensity than the first study had originally suggested. Three of the added obstacle items were perceived as both intense and frequently occurring and thus scored higher than 10 th position on obstacle intensity.

\section{Obstacles}

The mean scores for perceived intensity for items in the obstacle section were higher than the scores in the original study. This finding suggests that serious deficiencies in end-of-life care continue to exist and either may be getting worse or may be more obvious because nurses are more cognizant of deficiencies in care. Another possibility is that this sample of highly experienced nurses perceived these obstacles as being more intense than the initial study nurses did because the nurses who responded to the survey for this study cared for the sickest ICU patients, who are more often at the end of life.

\section{Serious deficiencies in end-of-life care} in intensive care units continue to exist.

Of the 5 obstacle items added to the current study questionnaire, 3 (items 3, 4, and 10) were rated among the top 10 in intensity. All 3 are related to different aspects of physicians' behavior. The high ratings of these obstacles confirm the findings in the original study that nurses experience these added items as additional obstacles to providing end-of-life care.

The obstacle perceived as the most intense was having patients' family members continually call a nurse for updates on the patients' condition. This obstacle was also the No. 1 obstacle in the original study, because frequent telephone calls directly stop nurses from providing care. In addition, critically ill patients cannot communicate on their own and therefore require another person, a nurse or a significant other, to become the gatekeeper of information about their condition. For patients' families, 
however, the same technology that is used to monitor a patient's current condition and allows rapid interventions is also the most sensitive to electrical interference; therefore, few types of cell phones can be used in ICUs and so contacting patients' family members from outside the hospital is difficult. This protective ICU environment isolates patients' families so that the families' need to remain close to their ill loved ones competes with trying to communicate with others outside the hospital. A patient's family members can make calls from the waiting room telephone, but incoming calls to the family members must almost always be routed through the unit to the patient's nurse.

The problem of numerous incoming phone calls is not new. Medland and Ferrans ${ }^{26}$ recognized that providing information about a patient's status was an essential part of patients' care; however, they also realized that frequent interruptions by patients' families created an additional burden for the patients' nurses. These investigators $^{26}$ used a 2-group, pretest, posttest quasi-experimental design with 30 family members of patients in a medical ICU to test a structured communications program. The program consisted of a 3-step process in which half of the families were formally introduced (within 24 hours of the patient's admittance) to unit procedures for accessing information on the patient's status, were given an informational pamphlet, and were called daily (by the patient's nurse) to inform them of the patient's current condition. The other 15 families served as the control group. Medland and Ferrans found that the number of incoming calls from the experimental group was significantly lower than the number from the control group. Further, in the experimental group, both satisfaction with care and the family members' perceptions of how well their information needs were met increased significantly compared with pretest data.

The second most intense obstacle in our study was having patients' family members not understand what using lifesaving measures might really mean to a patient. A possible explanation for this highly rated obstacle can be found in a study by Pierce. ${ }^{27}$ Pierce interviewed 29 family members of 75 decedents (39\% participation rate) and reported that families wanted to have everything possible done for their dying family members; however, everything possible did not necessarily mean medical interventions. In these participants' minds, doing everything meant being physically close to the patient, touching, talking, and keeping the patient clean and comfortable. A majority (62\%) also wished that caregivers had given the families more information about the patients' status and wished to have the information addressed in a more blunt and direct manner than it usually was.
The obstacle with the third highest perceived intensity score was nurses' perceptions that physicians involved in caring for a patient often disagreed about the goals of the patient's care. Physicians' disagreements about treatment and care goals caused much staff confusion and increased the nurses' work because the nurses then tried to act as arbitrators.

\section{Supportive Behaviors}

The ranges of mean scores for supportive behaviors were much higher than the ranges for obstacles because the behaviors with the highest scores were usually behaviors that a nurse could control and thus were perceived as being very helpful. Other more frequently occurring items were related to supportive behavior toward nurses that was provided by either a patient's family or by other staff members. Items perceived as both helpful and frequently occurring (high perceived supportive behavior scores) were, again, behaviors usually in the control of nurses. Behaviors controlled by physicians received lower scores mainly because these behaviors occur less often than do nurse-controlled behaviors.

Additionally, many of the supportive behaviors dealt with supporting a patient's family after the patient's death; only a single obstacle item concerned a care behavior implemented after a patient's death. The time after a death tends to evoke more helpful, nurturing behaviors than does the time preceding death, which is more likely to have obstacles that constrain ideal care of patients.

In summary, in terms of intensity, the order of items on supportive behavior changed very little between the original study and this study. Supportive behaviors that occurred most often were behaviors that nurses control. Other more frequently occurring items were related to supportive behavior for nurses provided by either a patient's family or by other staff members. Items perceived as both helpful and frequently occurring (high perceived supportive behavior score) were, again, usually in the control of nurses. Behaviors controlled by physicians had lower perceived supportive behavior scores mainly because these behaviors are perceived to occur less frequently than do nurse-controlled behaviors. Having similar items (on both the obstacle and supportive behaviors sections) score in the same direction supports the notion that the questionnaire was consistent, much as a reverse scoring item would do. ${ }^{28}$

\section{Recommendations}

Issues associated with communication of information about a patient's condition, use of treatments in 
hope of a meaningful recovery, and agreement with the current plan of care are obstacles to providing endof-life care in ICUs. Knowing the intensity and frequency of obstacles and supportive behaviors is an important step in developing meaningful interventions that improve end-of-life care.

Recommendations for decreasing the intensity and frequency of the obstacles that had the highest scores in our study include the following:

- Explore new ways of disseminating information about patients to the patients' family members on a regular basis to diminish the number of incoming calls handled by nurses.

- Educate physicians and nurses about the wishes of patients' family members for direct, clear, and honest information on patients.

- Clarify with patients and their family members their understanding of terms such as lifesaving measures to ensure that all who are involved clearly understand how treatment options might really affect the patients.

- Educate and encourage physicians to communicate directly, in a more open manner, with each other and with patients and patients' families.

\section{ACKNOWLEDGMENTS}

This study was funded, in part, by the Brigham Young University College of Nursing.

Commentary by Mary Jo Grap (see shaded boxes).

\section{REFERENCES}

1. Minino AM, Arias E, Kochanek KD, Murphy SL, Smith BL. Deaths: final data for 2000. Natl Vital Stat Rep. 2002;50:1-119.

2. Anderson RN, Kochanek KD, Murphy SL. Report of final mortality statistics, 1995. Mon Vital Stat Rep. 1997;45(suppl 2):18.

3. McCullough WB. Witnessing death versus framing death. In: Spiro HM, Curnen MGM, Wandel LP, eds. Facing Death: Where Culture, Religion, and Medicine Meet. New Haven, Conn: Yale University Press; 1996:184-189.

4. Mularski RA, Osborne ML. End-of-life care in the critically ill geriatric population. Crit Care Clin. 2003;19:789-810, viii.

5. Angus DC, Barnato AE, Linde-Zwirble WT, et al. Use of intensive care at the end of life in the United States: an epidemiologic study. Crit Care Med. 2004;32:638-643.

6. Chapple HS. Changing the game in the intensive care unit: letting nature take its course. Crit Care Nurse. June 1999;19:25-34.

7. Perkin RM, Young T, Freier MC, Allen J, Orr RD. Stress and distress in pediatric nurses: lessons from Baby K. Am J Crit Care. 1997;6:225-232.

8. Anderson CA. Flawed research: is it the design, methods, or the wrong conclusions? Nurs Outlook. 1996;44:209-210.

9. Baggs JG, Schmitt MH. Intensive care decisions about level of aggressiveness of care. Res Nurs Health. 1995;18:345-355.

10. Maeve MK. A critical analysis of physician research into nursing practice. Nurs Outlook. 1998;46:24-28.

11. The SUPPORT Principal Investigators. A controlled trial to improve care for seriously ill hospitalized patients: the Study to Understand Prognoses and Preferences for Outcomes and Risks of Treatments (SUPPORT). JAMA. 1995;274:1591-1598.

12. Alspach G. Providing care for the dying: one answer, many questions. Crit Care Nurse. October 1997;17:14, 16-17.

13. Ahrens T, Yancey V, Kollef M. Improving family communications at the end of life: implications for length of stay in the intensive care unit and resource use. Am J Crit Care. 2003;12:317-323.

14. Baggs JG. End-of-life care for older adults in ICUs. Annu Rev Nurs Res. 2002;20:181-229

15. Fins JJ, Miller FG, Acres CA, Bacchetta MD, Huzzard LL, Rapkin BD. End-of-life decision-making in the hospital: current practice and future prospects. J Pain Symptom Manage. 1998;17:6-15.

16. Ferrell B, Virani R, Grant M, Coyne P, Uman G. Beyond the Supreme Court decision: nursing perspectives on end-of-life care. Oncol Nurs Forum. 2000;27:445-455.

17. Oliverio R, Fraulo B. SUPPORT revisited: the nurse clinician's perspective. Study to Understand Prognoses and Preferences for Outcomes and Risks of Treatment. Holist Nurs Pract. October 1998;13:1-7.

18. Stanley KJ. End-of-life care: where are we headed? What do we want? Who will decide? Innov Breast Cancer Care 1998;4:3-8.

19. Puntillo KA, Benner P, Drought T, et al. End-of-life issues in intensive care units: a national random survey of nurses' knowledge and beliefs. $\mathrm{Am}$ J Crit Care. 2001;10:216-229.

20. Kirchhoff KT, Beckstrand RL. Critical care nurses' perceptions of obstacles and helpful behaviors in providing end-of-life care to dying patients. Am J Crit Care. 2000;9:96-105.

21. Kirchhoff KT, Spuhler V, Walker L, Hutton A, Cole BV, Clemmer T. Intensive care nurses' experiences with end-of-life care. Am J Crit Care. 2000;9:36-42.

22. Campbell ML. End of life care in the ICU: current practice and future hopes. Crit Care Nurs Clin North Am. 2002;14:197-200, ix.

23. Sawatzky JA. Stress in critical care nurses: actual and perceived. Heart Lung. 1996;25:409-417.

24. Nelson-Marten P, Braaten J, English NK. Critical caring: promoting good end-of-life care in the intensive care unit. Crit Care Nurs Clin North Am. 2001; 13:577-585.

25. Wagner LI, Jason LA. Outcomes of occupational stressors on nurses: chronic fatigue syndrome-related symptoms. Nursingconnections. Fall 1997; 10:41-49.

26. Medland JJ, Ferrans CE. Effectiveness of a structured communication program for family members of patients in an ICU. Am J Crit Care. 1998;7:24-29.

27. Pierce SF. Improving end-of-life care: gathering suggestions from family members. Nurs Forum. April-June, 1999;34:5-14.

28. Burns N, Grove SK. The Practice of Nursing Research: Conduct, Critique. 3rd ed. Philadelphia, Pa: WB Saunders Co; 1997. 
Copyright of American Journal of Critical Care is the property of American Association of Critical Care Nurses. The copyright in an individual article may be maintained by the author in certain cases. Content may not be copied or emailed to multiple sites or posted to a listserv without the copyright holder's express written permission. However, users may print, download, or email articles for individual use. 